\title{
Viaje por el universo de la palabra
}

\section{A trip by the universe of the word}

\author{
Celso Román* \\ ftdelatierra@yahoo.es \\ Fundación Taller de la Tierra
}

\section{RESUMEN}

Este artículo realiza un viaje por el universo de la palabra como estrategia adecuada para enseñar la literatura a niños y jóvenes. Con tal propósito, se apoya en la revisión de teorías pertinentes y su ilustración mediante un exhaustivo recorrido por las producciones literarias universales y locales. En este viaje, se detiene en varias estaciones que se corresponden con el desarrollo de la humanidad. La primera de ellas se remonta a los mitos y expone referencias que explican la creación del mundo y los seres humanos. La segunda estación se detiene en las leyendas y su particular manera de instruir sobre sucesos históricos. Llega luego a la estación del cuento donde destaca los cuentos populares europeos nutridos con el crisol cultural de Oriente. Finalmente, hace una escala especial en el cuento colombiano caracterizado por formas propias provenientes de la mezcla de la herencia europea con la sangre indígena y negra.

\section{Palabras clave}

enseñanza, literatura infantil y juvenil, mito, leyenda, cuento.

\section{ABSTRACT}

The article makes a journey by the universe of the word like a suitable strategy to teach Literature to children and young people. In that sense the text is supported by pertinent theories and it is illustrated by means of an exhaustive route by the universal and local literary productions. In this trip the reader stops in several stations that correspond with the development of the humanity. The first stop goes back to myths and it exposes.references that explain the creation of the world and the human beings. The second one stops in the legend and their particular way to instruct on historical events. It arrives soon at the station of the story where it emphasizes nourished European popular stories with the cultural crucible of East. Finally the text makes a special scale in the Colombian story characterized by originating own forms of the mixture of the European inheritance with the indigenous and black blood.

\section{KEY WORDS}

Teaching, Education, infantile and youthful Literature, myth, legend, story

* Escritor. Subdirector de la Fundación Taller de la Tierra. 


\section{Introducción}

$\mathrm{L}$ a intención de este texto sobre la literatura infantil y juvenil es invitar a los lectores a un viaje por el universo de la palabra, pues considero que la literatura se puede enseñar contando cuentos.

Para ello, es necesario despojarnos de las estructuras académicas y de las categorías -literarias o no- en las cuales siempre algunos tipos de escuelas han querido encasillar los cuentos, con la muy buena intención de facilitar su conocimiento y estudio, pero casi siempre ignorando que la literatura está viva, que, en el principio, fue la palabra la creadora del mundo, como lo dicen la Biblia (1960) y muchas culturas indigenas, de las cuales veremos algunos ejemplos a lo largo de este viaje.

\section{El principio y el poder de la palabra}

Empezaremos el viaje, estimados lectores, remontándonos al pasado de la humanidad, pues "los cuentos nos distinguen más de los animales que el pulgar oponible", como lo afirma Jane Yolen (1986), norteamericana recopiladora de literatura tradicional. Por su parte, "la narrativa es tan antigua como la humanidad", escribe Roland Barthes (1992).

En la infancia de nuestra especie, los antepasados fueron un puñado de asustados homínidos que se refugiaban en cavernas tratando de sobrevivir en un medio hostil, circundados por fieras y expuestos a la adversidad y la inclemencia del tiempo. Era necesario explicar, con la palabra, el origen del mundo y de las cosas. ¿Quién nos puso aquí? ¿Cómo fue la creación del mundo $\mathrm{y}$ los seres humanos?

El Popol-Vuh, libro sagrado de los mayas, dice que:

[...] todo estaba en suspenso, todo en calma, en silencio; todo inmóvil, callado, y vacía la extensión del cielo. No se manifestaba la faz de la tierra. Sólo estaban el mar en calma y el cielo en toda su extensión. Solamente había inmovilidad y silencio en la oscuridad, en la noche.

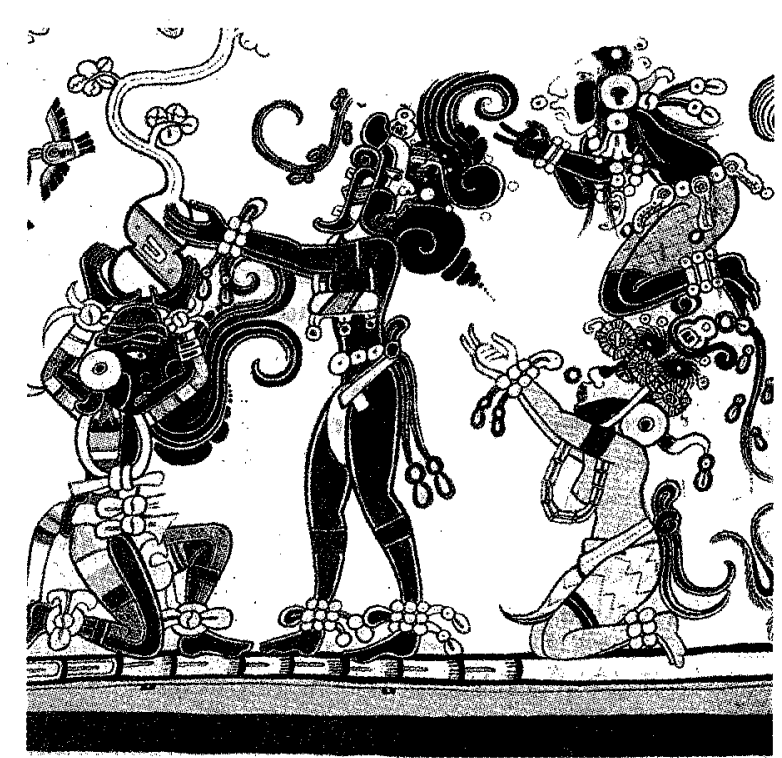

Sólo el Creador, el Formador, Tepeu, Gucumatz, los Progenitores, estaban en el agua rodeados de claridad. Llegó aquí entonces la palabra, vinieron juntos Tepeu y Gucumatz, en la oscuridad, en la noche, y hablaron entre sí [...] se pusieron de acuerdo, juntaron sus palabras y su pensamiento. [...] conferenciaron sobre la vida y la claridad, cómo se hará para que aclare y amanezca, quién será el que produzca el alimento y el sustento.

¡Hágase así! ¡Que se llene el vacío ¡Que esta agua se retire y desocupe, que surja la tierra y que se afirme! Así dijeron. ¡Que aclare, que amanezca en el cielo y en la tierra! No habrá gloria y grandeza en nuestra creación y formación hasta que exista la criatura humana, el hombre formado. Así dijeron.

Luego la tierra fue creada por ellos. Así fue en verdad como se hizo la creación de la tierra: - jierra!, dijeron, y al instante fue hecha. (2000: 25)

En los mitos de creación de muchas culturas hay una coincidencia respecto a que, al principio, había tinieblas. Aclaro que aquí uso el término mito en el sentido de una explicación del mundo en la cual intervienen seres todopoderosos, con fuerzas superiores a las de los simples seres humanos. Para Rocío Vélez de Piedrahita: 
[...] el Mito, de origen religioso, puede llegar a divertir pero no es esa su meta. Se refiere a sucesos ontológicos -es decir, referentes a la creación-, por lo general en tono pesimista, trágico. El héroe es, o inhumano -un dioso termina por ser un híbrido fenomenal y se convierte en semidiós; sus metas están en el más allá; los triunfos no son prácticos, tangibles, sino premios y castigos en otra vida. Con frecuencia terminan mal, con castigos eternos. (Vélez de Piedrahita, 1986: 47)

Para los muiscas "al principio del mundo la luz estaba encerrada en una cosa grande que no saben describir y que se llama Chiminigagua o el creador; lo primero que salió de allí fueron unas aves negras que volando por todo el mundo lanzaban por los picos un aire resplandeciente con que se iluminó la tierra"(Uricoechea, 1984: 78)

Veamos la explicación de la creación de los seres humanos para los antiguos habitantes del altiplano cundiboyacense:

[...] el mundo se pobló de la manera siguiente: poco después que amaneció el primer día, salió de la laguna de Iguaque, cuatro leguas al norte de Tunja una mujer hermosa llamada Bachué o Fuzachogua, que quiere decir mujer buena, con un niño de tres años. Bajaron luego a lo llano, en donde vivieron hasta que ya adulto el niño, casó con la Bachué, y en ellos comenzó el género humano, que se propagó con extraordinaria rapidez. Pasados muchos años, viendo la tierra poblada, volvieron a la misma laguna, y convirtiéndose en serpientes, desaparecieron en las aguas. (Uricoechea, 1984: 82)

En la Biblia, que soporta gran parte de las convicciones religiosas de nuestra cultura, se dice en el Génesis 1; 2-5:

Y la tierra estaba desordenada y vacía, y las tinieblas estaban sobre la faz del abismo, y el Espíritu de Dios se movía sobre la faz de las aguas.

Y dijo Dios: Sea la luz, y fue la luz.

Y vio Dios que la luz era buena; y separó Dios la luz de las tinieblas. (1960: 29)
Todos aprendimos que, posteriormente, Dios pobló el mundo con toda clase de plantas y animales, y que luego creó los seres humanos "a su imagen y semejanza".

Para los esquimales, como para los muiscas, también:

[...] en el principio había sólo oscuridad. Sin embargo, en esa penumbra ya existía el cuervo, acurrucado, escuchando. No se oía nada. Palpó a su alrededor. Estaba en un terreno duro y baldío. Con mucha precaución al principio, y después con más confianza, empezó a arrastrarse, y por donde iba pasando, surgían las cosas: los arroyos, los ríos, los bosques.

Pero no había llegado muy lejos cuando tuvo que detenerse, pues estaba al borde de un profundo abismo. Se paró al borde, extendió sus alas y supo quién era: Tulugaukuk, el Padre Cuervo, creador de toda la vida. Se lanzó a volar y encontró un lugar desolado al que llamó "tierra", para diferenciarlo del "cielo", que era el borde del abismo de donde había venido.

Llenó todo de vegetación y de ríos, pero la oscuridad todavía lo cubría todo, hasta que descubrió un punto de luz, semioculto en el suelo, que llamó su atención. Era un fragmento de mica, que se hacía más brillante a medida que lo desenterraba con el pico. Cubriéndose los ojos para evitar el resplandor, lo arrojó al aire y el sol quedó suspendido, llenando todo de luz y permitiendo ver la hermosura de la creación.

El cuervo paseó por esta linda tierra, orgulloso de su trabajo, y en una playa vio una bella planta de fríjol, tan alta como un árbol y llena de vainas verdes. De pronto, una de ellas se abrió y salió el primer esquimal. El cuervo le enseñó a comer frutas, pero ese hombre siguió con hambre. Entonces el cuervo tomó un puñado de barro de la orilla del río y modeló parejas de animales: bueyes almizcleros, caribúes, focas, $\mathrm{y}$ todos los que hoy pueblan la tierra. Luego batió las alas sobre ellos, y cobraron vida para servir de alimento a los esquimales. (Word y Sibbick, 1987: 32) 
Para los indígenas de Norteamérica:

Había un mundo antes de este que vivimos en el presente; había un mundo de la primera gente, que eran diferentes a nosotros. Eran muy numerosos, tanto, que si pudiéramos contar todas las estrellas del cielo, todas las plumas de los pájaros, todos los pelos en las pieles de los animales, todos los cabellos de nuestras propias cabezas, no serían tan numerosos como la primera gente.

Ese pueblo vivió mucho tiempo en paz, en concordia, en armonía, en felicidad. Ningún hombre sabe, ningún hombre puede decir que tanto vivieron de esa manera. Al final cambiaron las mentes de todos, excepto de un pequeño número de ellos; cayeron en el conflịcto, uno ofendió al otro conciente o inconscientemente, con intención o sin intención uno injurió al otro, uno quiso alguna cosa en especial, el otro también quiso esa misma cosa.

El conflicto se estableció, y a causa de esto vino un tiempo de actividad y lucha, el cual no acabó o se detuvo hasta que la gran mayoría de esta primera gente -esto es, todos excepto un pequeño número- se convirtieron en las diferentes clases de criaturas vivientes que existen o han existido sobre la tierra, excepto el hombre, es decir todas las bestias, pájaros, reptiles, peces, gusanos e insectos, así como árboles, plantas, hierbas, rocas y algunas montañas; ellos fueron convertidos en todo lo que vemos en la tierra o en el firmamento.

Ese pequeño número de los antiguos que no pelearon, esa gran primera gente de los viejos tiempos que permanecieron unidos en pensamiento y en armonía dejaron la tierra, navegaron alejándose hacia el occidente, pasaron esa línea donde el cielo desciende y toca la tierra, enrumbaron hacia lugares más allá; permanecieron allí o se dirigieron a las regiones superiores y vivieron allí felizmente, en armonía y acuerdo, así viven hoy, y vivirán por siempre". (Curtin, 1995: 375)
Entre nuestros indígenas Murui-Muinane, de la Amazonia, la creación del mundo también está relacionada con la palabra:

En el principio nada había aquí. Nuestro $\mathrm{Pa}$ dre, el que nos creó, no tenía extremidades, carecía de miembros. Era corazón únicamente: el corazón que habla. Era un corazón bueno.

Buscaba la manera de dar vida. Meditaba la forma de hacer la creación. Entonces indagó cómo había aparecido él mismo.

El solitario corazón comenzó a hablar, a decir palabras dulces, llenas de buena fe, plenas de buena intención.

Con las palabras de ese buen corazón fuimos creados.

Dijo: "Ya di vida a mi prole. Ahora pondré a uno de ellos, al mayor, en reemplazo mío. Se llamará Hombre-de-Yuca".

E1 Creador no aconsejaba. Sólo contaba historias. No puso sobre aviso al primogénito, por eso era aún débil, no eran rectos sus senderos.

Hombre-de-Yuca comenzó a contar historias a las gentes como si fueran propias, suplantando a su padre, pero antes del momento indicado.

Se presentó como El Sabedor: el que transita los caminos del sueño sin estar dormido y busca y ve.

Se presentó como el que sabe indagar los comienzos.

Se presentó como el que sabe indagar el final.

Como el que hace que la gente nazca fuerte, igual a un plantío que medra en tiempo bueno.

Se presentó como dueño de las tradicionēs. Como el que conoce el origen de todas las tribus. El que sabe del inicio y destino de los brujos primordiales. 
- Yo soy -dijo- el que habla de las frutas, de su origen y de cómo quedaron en poder de las gentes y de los bailes y adivinanzas que les son propios.

- Yo soy el que se asoma para descubrir quién aparece en la distancia.

Yo soy el relámpago que ilumina; el que sabe del nacer que es abrirse paso del vientre hacia la luz.

- Yo soy el caudillo, el que ordena, el que distribuye los oficios.

Eran los nombres del Creador. Eran las palabras buenas. El Padre habló así:

- Hijo, con estas palabras puedes ayudar a los demás. Están bien formuladas. Todo dependerá de ti para que la gente medre. Dirás al presentarte: Yo soy Hombre-de-Yuca, Yo soy Fuerza-Omnipotente, cabeza principal. (Niño, 1978: 35)

\section{Se establecen los seres humanos}

Nuestra ventaja sobre las bestias empezó cuando descubrimos el fuego, y a su vez la palabra que explica su magia. Veamos un ejemplo de esa leyenda, según la cuentan en África:

Hace mucho, mucho tiempo, la gente no conocía el fuego. No podían cocinar, ni forjar el hierro, ni cocer las ollas de arcilla, y tenían que comer carne cruda. Un cazador se había alejado mucho de su aldea persiguiendo un pájaro de brillantes colores, cuando vio en la distancia algo que jamás había contemplado: una nube delgada que se elevaba en el aire en línea recta, y preguntándose qué podría ser, se acercó sin alcanzarla hasta que llegó la noche. Cuando creyó que la había perdido en medio de la oscuridad, vio un resplandor que tenía un brillo variable, como el de una estrella. Al aproximarse pudo darse cuenta que las luces cambiaban como lenguas que se elevaban y desprendían la nube que había visto en la distancia.

Al arrimarse lo sintió tan agradable, móvil y caliente en medio del frío de la noche, que sin duda pensó que se trataba de un espíritu poderoso y le habló con cortesía:

- Te saludo, gran jefe.

- Bienvenido humano, puedes pasar la noche conmigo y calentarte pero tendrás que alimentarme con ramas, arbustos, hojas, cañas, hierbas, y troncos secos.

El cazador obedeció y vio cómo crecía el fuego cuando se le alimentaba como él decía:

- Si quieres comer, mira detrás de ti, le dijo el fuego.

El cazador se volvió y notó un conejo que miraba hipnotizado el resplandor de las llamas. Rápidamente lo mató de un flechazo y cuando se disponía a comer la carne cruda, como era su costumbre, el fuego volvió a hablarle:

- Acércate y asa tu comida, así te gustará más.

“AAsar?”. El cazador no conocía esa palabra, ni tampoco "llama", "humo" o "fuego", hasta que el espíritu se lo explicó. Después de probar la carne asada, el hombre decidió que jamás volvería a consumirla cruda, y también tomó la decisión de llevar el fuego a su aldea, para que todos pudieran disfrutar de sus beneficios.

Así se lo propuso al fuego, prometiéndole alimentarlo y cuidarlo bien por el resto de su vida.

- No, sería peligroso para ti y para los demás seres vivos, dijo el fuego regándose con cortesía pero también con firmeza.

El hombre se acostó a dormir, y cuando el sol asomaba por el horizonte, tomó una de las ramas gruesas de la hoguera y huyó con ella rumbo a su aldea, dejando tras de sí un reguero de chispas. Pero mientras corría, el fuego enfurecido por la desobediencia consumió la rama hasta que quemó las manos del cazador y él tuvo que soltarla. Con un grito de dolor la dejó caer y siguió corriendo. No había avanzado mucho cuando oyó a sus espaldas un gran rugido. Al volver la cabeza, se dio cuenta que el fuego, mucho más grande que antes, con llamas aterradoras, le seguía.

El fuego atravesó la sabana detrás del hombre devorando primero las hierbas, luego los 
arbustos y por fin los árboles. Parecía crecer $y$ dividirse en varios torrentes de llamas que avanzaban impulsados por el viento hasta quemar la sabana de un extremo a otro.

Parecía que el mismo cielo y las estrellas iban a arder. El cazador se dio cuenta que el fuego nunca quemaba dos veces un mismo lugar: una vez que había devorado una zona, no volvía a ella, y lo vio avanzar hasta que un río lo detuvo.

Para entonces había destruido varias aldeas, pero los habitantes lograron salvarse vadeando el río. Cuando retornaron a las ruinas de sus cabañas, descubrieron que sus reservas de alimentos se habían quemado, pero como tenían tanta hambre, trataron de aprovechar lo que quedaba, y con gran sorpresa, comprobaron que esa comida cocida por el calor sabía mucho mejor que la que estaban acostumbrados a comer cruda. También vieron que sus ollas y utensilios de arcilla estaban más duros y soportaban la humedad.

Desde entonces los seres humanos firmamos un pacto de paz con el fuego, comprometiéndonos a convivir con él, alimentándolo sin dejarlo enfurecer, para que a cambio nos calentara en la noche, nos acompañara y nos permitiera la cocción de los alimentos y de la alfarería. (Knappert y Pelizzoli, 1988: 67)

Con la palabra, el narrador crea el mundo y es mediante ella que los seres humanos estructuramos el universo, lo aprehendemos e interactuamos con él.

En este viaje, hemos visto cómo surgen las explicaciones del mundo en diversas culturas, y entramos en un campo nuevo con un término que acaba de aparecer: leyenda, y quiero dejar claro que al mencionarla, y como ustedes pudieron apreciarlo en el texto, hay una relación entre un ser humano, el cazador, y un dios -o al menos un espíritu poderoso, que en este caso es el fuego. Rocío Vélez de Piedrahita afirma que "la le-

\section{nalidad es instruir" (1986: 55).}

yenda se apoya en un suceso histórico lejano, sus metas son idealistas; los premios abstractos, poco prácticos la fama póstuma, el honor, etc. $-y$ acaban por lo general con la muerte, gloriosa pero muerte, del héroe, a veces con un fuerte deje pesimista. [...] La leyenda puede divertir, pero su fi-

Damos un salto en el tiempo para recordar-los que tenemos ancestro tolimense- cómo, en las noches de tierra caliente, la tía 'Celmira nos llenaba de pavor contándonos la leyenda de la Patasola y su palabra tenía el poder de hacernos temblar de miedo cuando la oscuridad se llenaba de venados encantados, voces de espanto y fantasmas que nos hacían erizar la piel para que fuéramos niños obedientes.

Transcribo una versión de Milagros Palma que la cuenta muy parecido a como lo hacía la tía, en una mesa con nueve niños temblando de miedo alrededor de una sola vela encendida. Terror puro:

En Semana Santa dos muchachos decidieron trabajar en un pedazo de tierra, en medio del monte, que les había cedido el patrón de la finca [primer error, ya que ese tiempo no se debe trabajar $]^{1}$. Ya caía la tarde del miércoles Santo cuando llegaron al pequeño rancho de palma que habían levantado, y estaban pelando una gallina para la cena. De pronto un grito delgadito rompió la quietud. Floro, el mayor, asustado paró el oído mientras el hermano contestaba con otro grito. Al repetirse el grito, Floro regañó al hermano sabiendo del peligro en la soledad de la selva.

Custodio, con una carcajada, dijo a su hermano que se dejara de güevonadas. Los cuentos de viejas le provocaban risas. El grito se oyó cada vez más cerca. Custodio pensó que pudiera ser el de un niño, o el de una mujer perdida en la

1 Nota del autor de este artículo. 
selva, pero de pronto apareció frente a la entrada del rancho de palma una mujer hermosa, con un sombrero de paja, vestida de verde. Una mujer lindísima que caminaba con pasos inciertos, como si estuviera con los pies adoloridos, maltratados por la marcha. Ella contó que andaba huyendo de su padre, un terrateniente de la región, que no la dejaba salir ni andar con muchachos. La joven, con una sonrisa de dicha, daba gracias al cielo por haber encontrado refugio, ya que había tenido mucho miedo de que se le apareciera una fiera en su larga marcha, pues no tenía con qué defenderse.

Floro no creyó esas vainas, pero Custodio sintió compasión por la joven que después de todo necesitaba protección. Sin saber cómo ni cuándo se sintió pegado a la mujer. Para la comida, ella se sentó al lado de Custodio. Floro, desconfiado como siempre, empezó a sentir miedo, un cierto recelo. La noche se anunciaba maravillosa para Custodio. Hablaron de la finquita, del trabajo que debían hacer para sacar algunas ganancias y antes de acostarse, prendieron una hoguera en el piso de tierra.

A medida que el tiempo pasaba y se acercaba la media noche, Custodio y la muchacha parecían una pareja de enamorados, agarrados de la mano, hablándose al oído. Estaban pegados, el uno contra el otro. Floro se cansó de hacer señas para prevenir a su hermano del peligro. Pero Custodio, que estaba peor que un perro en celo, se subió al zarzo con la mujer. Floro se acostó junto a la hoguera, sobre unos costales, con su perro al lado. Lleno de presentimientos dejó el machete y la escopeta junto a él, y como no se podía dormir, se puso a rezar. $\mathrm{El}$ pobre hombre pasó con un credo en la boca, con un presentimiento feo.

Los enamorados murmuraban y se revolcaban en el zarzo. La mujer gemía y floro gruñía, rebuznaba de placer hasta caer vencido por el sueño. Su hermano escuchaba con curiosidad el relincho de los enamorados. La hoguera estaba apagada, los troncos, quemados; unos cuantos carbones envueltos en cenizas.
De repente escuchó unos ruidos extraños y sintió su cuerpo embebido, como si hubiera sudado toda la noche. Acosado por la humedad pegajosa de su ropa y por un olor a fiera, prendió la linterna de cuatro tacos. Estaba salpicado de sangre. Inmediatamente cayó en la cuenta de que la mujer era la Patasola que se estaba comiendo a su hermano.

Arriba se oía un ruido, como si un perro estuviera comiendo huesos. Pero el perro estaba con el rabo entre las patas, quietecito, junto a él. El animal tenía los ojos desorbitados haciendo toda clase de muecas, como queriendo ladrar, sus aullidos mudos aumentaban el pánico de Floro que estaba apunto de cagarse en los pantalones.

Cuando sintió que iba a caer privado del miedo, Floro se metió en la boca la medalla de la Virgen del Carmen que llevaba al cuello. Entonces se levantó movido por una extraña fuerza, se amarró el machete a la cintura, llamó al perro y se fue arrastrando un rejo para que no lo siguiera la Patasola. Con el hacha y la linterna arrancó a correr. Se sentía desmayar, los pies se le volvían cada vez más pesados, sentía que iba a perder el sentido, pero anduvo por la selva sólo con la linterna y el perro aullando.

No se sabe cuánto tiempo caminó, pero con las primeras luces del amanecer se topó con una casa. La puerta se abrió con sólo tocarla y la gente lo vio caer sin sentido. Floro volvió en sí con tragos de aguardiente y pocillos de agua de panela caliente que le dio la mujer de la casa. Entonces, cuando se vio a salvo, contó lo que le había sucedido. Después del desayuno, los campesinos se fueron con el señor de la hacienda y armados con palos, machetes y escopetas, se metieron selva adentro.

A la finquita llegaron con el sol a la mitad del cielo y en la choza encontraron un reguero de sangre sobre los sacos. En el zarzo estaban los huesos de Custodio, pelados, regados por todas partes, completamente limpios, como si los hubieran lavado. Con los huesos en un saco regresaron a la hacienda. 
Después de poner la denuncia en la comisaría del pueblo, se velaron los huesos en un cajón y se hizo un entierro muy alegre, con rosquillas, café y aguardiente.

La gente estaba aterrada, todo el mundo sabía que sólo la Patasola podía hacer esas cosas. Eso no podía ser un animal porque ni una fiera, ni un jaguar, ni un oso se podían comer de una sentada a un hombre entero, dejando los huesos tan lamidos, limpiecitos. Esas cosas no suceden jamás. Sin embargo, casos como éste han ocurrido en veredas y pueblos de esta región, y han quedado en la memoria de generaciones enteras. (1993: 49)

\section{Desde Europa hasta América}

Hemos dado un salto a Colombia con el pretexto de la leyenda, pero, en este viaje con la palabra a través de los tiempos, hemos visto primero a los dioses creando el mundo, a los seres humanos interactuando con dioses o seres fantásticos para dar origen a las leyendas, y es hora de que veamos las historias que le suceden a los seres humanos, simple y llanamente, en los cuentos. Y aquí es donde las categorías se nos van al traste, porque en los cuentos aparecen seres mitológicos, y el ingenio humano se las arregla para escapar muchas veces con una sonrisa de picardía.

Se han creado numerosas denominaciones de algo que es el resultado de la confluencia de innumerables creaciones de la humanidad a lo largo de los siglos y las diferentes culturas, que por diversos caminos han llegado hasta nosotros. Estoy refiriéndome a los cuentos populares que, de manera global, han sido llamados cuentos folclóricos, cuentos de hadas, cuentos tradicionales o simplemente relatos maravillosos o textos folclóricos.

Para dar un poco de claridad a esto que parece un verdadero embrollo, podemos establecer unas líneas generales, que nos permitan disfrutarlos. Para Jane Yolen, "las historias acumuladas por las muchas sociedades del planeta son un verdadero catálogo de pueblos, lugares, eventos y maravillas. A menudo tales cuentos son descritos como 'historia cultural', en la medida en que constituyen un cuerpo fijo de saber -lore- popular - folk- (de donde viene, en inglés, el término folklore)" (1986: 12).

En este sentido, Rocío Vélez de Piedrahita (1986) hace una prolija enumeración de cómo los cuentos populares europeos se forjaron en un verdadero crisol cultural nutriéndose de los dragones y personajes como la Cenicienta, venidos desde la lejana China con los mercaderes que transitaban la ruta de la seda, de perfumes mágicos, alfombras voladoras, genios, manjares abundantes, ogros, talismanes y culebras de siete colas originarias de la India por el camino de las especias y durante las cruzadas. De Persia y Arabia, llegaron las Mil y una noches (Anónimo, 1998) y relatos populares cantados por los juglares durante los siglos X, XI Y XII (Menéndez Pidal, 1924) a una Europa donde ya hacían presencia las fábulas del griego Esopo (1995) y los numerosos personajes de la mitología celta como hombrecitos (little men), enanos, elfos, trolls, príncipes, princesas, los caballeros de la mesa redonda del Rey Arturo, magos como el famoso Merlín, hadas como Morgana, además de espadas, escudos y sortilegios mágicos (Zimmer, 1997). Europa en los siglos XviII y XIX empezó la recopilación sistemática de estos cuentos populares en las obras y adaptaciones de G. B. Basile, Clarles Perrault, los hermanos Jacob y Wilhelm Grimm, Hans Christian Andersen (1992) y colecciones de cuentos populares noruegos (Norsk folkeeventyr), 1841-44, de P. S. Absjörsen, J. Jacobs y J. E. Moe (Jorgenson, 1933).

En España, esta literatura tuvo, además, la influencia de ocho siglos de ocupación mora en los califatos de Granada y Al Andalus -"nuestra Casa" -, hoy Andalucía (Peláez, 1988). De allí, pasó a América y llegó a nosotros con los misioneros y los conquistadores que trajeron sus romances, ánimas, apariciones y se encontraron en nuestro territorio con un nuevo crisol donde esa herencia se fundió en el campo con los mitos indígenas que aportaron su temor reverente a las fuerzas de la naturaleza, la magia del entorno y el bagaje cultural traído por los africanos traídos a la fuerza como mano de obra para las minas y los cañaduzales. De alli, llegaron la santería, los sortilegios y brujerías, monstruos de la selva y personajes como el tío conejo en su permanente 
rivalidad con el tío tigre. Nace una literatura rica en leyendas, mitos y cuentos de espantos y aparecidos (Oviedo, 1997).

Vladimir Propp, autor de lòs estudios Las raices históricas del cuento (1984) y "La estructura del cuento popular" (1985), analizó centenares de cuentos populares europeos y encontró en ellos una estructura común en la cual se pueden destacar los siguientes elementos: la presencia de un héroe que debe cumplir una misión; su partida o alejamiento, debido a la trasgresión de una prohibición; la presencia de donantes, o personas que le ayudan con objetos mágicos; la aparición de enemigos, con sus respectivos objetos mágicos que afectan al héroe; las diversas pruebas que debe sobrepasar en su camino hasta llegar al desenlace, la misión cumplida, la consecución de la felicidad, el amor y la riqueza.

El sicoanalista Bruno Bettelheim da una enorme importancia a los cuentos de hadas por cuanto ellos hablan al inconsciente profundo del niño, preparándolo para enfrentar positivamente las problemáticas que se le han de presentar en la vida adulta:

[...] la eventual salvación, la completa restauración y la elevación del niño-héroe a una condición superior de existencia, son características de los cuentos de hadas. En tanto que obras de arte, su propósito es no sólo enseñarnos que la vida es difícil e implica frecuentemente peligrosas batallas, sino también que sólo dominando las sucesivas crisis de nuestra existencia seremos capaces de encontrarnos a nosotros mismos. (Bettelheim, 1981: 132)

\section{Estamos en Colombia}

Hemos llegado a nuestra casa en este viaje con la palabra y toda la herencia europea del relato, mezclada con la sangre indígena y la negra, tomó formas propias en este suelo. Por eso, es posible encontrar en los campos colombianos ejemplos de cuentos tradicionales que tienen la estructura europea, pero ya se han "vestido" y pintado con los colores locales.

Entre los muchos recopiladores de cuentos tradicionales están don Tomás Carrasquilla (Por aguas y pedrejones, 1952), Antonio Molina
Uribe ( $A$ echar cuentos pues), Euclides Jaramillo Arango (Las aventuras del picaro tio Conejo, 1950), José Antonio León Rey (El pueblo relata, 1980) y Agustín Jaramillo Londoño (Cosecha de cuentos, 1858) (Mujica, 2004). De este último, quisiera transcribir, a manera de ilustración, y para comparar con la estructura del cuento español tradicional de "Los tres hermanos", el cuento "Casicón, Casico y Casiquito":

Est'era una pareja qui había hace años por aquí, en estas montañas...

Habían abierto su pedaz'e monte y trabajaban la tierra: sembraban yuca, maíz y frisol. Y un día mi Dios los bendijo y les nacieron tres hijos: trillizos. Ai mismo que nacieron el papá sembró tres naranjirtos en el patio de la casa: uno a un lao, otro en el medio y el otro al otro lao. Y los tres naranjitos fueron creciendo parejo con los muchachos, muy sanos y coposos.

Casimbo y Casima, que así se llamaban los padres, estaban muy orgullosos de sus hijos, que eran muy buenos.

Hasta que un día Casicón, el mayor de los tres hermanos, resolvió irse a andar.

Voy a buscame una mujer, pero la más linda que hayga, pa casame con ella- dijo.

Los padres consintieron, pero, antes de que se fuera, le dieron a cada uno de los hijos la herencia: un perro y una peinilla.

Se despidió Casicón de sus padres y de sus dos hermanos, Casico y Casiquito, y emprendió el camino.

A poquito andar topó un monte muy espeso y s'internó en él, a ver aond'iba a salir.

Cogió a andar y andar sin encontrar qué comer ni dar con un infeliz rancho ónde bogase un clarito tan siquiera.

Cuando ya iba muy agotao y no podía dar paso, clavó una cruz y se dejó caer: “ßBueno: 
hasta aquí llegué yo!", se dijo. Era de noche y se quedó dormido. Cuando dispertó ya era de día y se sintió con nuevas fuerzas. Volvió a emprender camino... Hasta que por fin y después de mucho andar, salió a una ciudá muy grànde. Preguntó por las más lindas, pero todas le parecieron feas. Así que no tuvo más remedio que echar pa'delante.

Llegó a una media poblacioncita que en los alrededores vivía una vieja que comía gente. Pero, como él no sabía la cosa, tocó a la puerta a pedir posada. La vieja se alegró mucho así que lo vió:

- ¡Claro! ¡Claro! -le contestó-. Déntrese, joven -De lo más zalñamera la vieja-. Sígase, que ya le voy a arreglar su buena comida y su buena cama.

Casicón, qu'estaba con más hambrè qui hast'ai, comió como un botao.

- Vea, mi don -le dice la vieja-. Lo único que no me gusta es ese perro que viene con busté. ¿A mí, acaso me gustan los animales? Tenga: amárrelo con esto allá ajuera. $Y$ si arrancó tres pelos de la cabeza, que cuando el muchacho fue a amarrar el perro, se convirtieron en tres cadenas.

Casicón si acomodó en un quicio a dale castigo a la tacita de mazamorra con qu'iba a asentar. $Y$, en esas, cuando menos lo pensó, se le viene encima la vieja con una trolempa di hacha. Se trabó el combate, pero la vieja al fin mató a Casicón y se lo comió. Y allá, muy lejos, Casimba dijo:

- Algo le pasó a mi muchacho, porque, o si no, ¿por qué se secó el naranjito?

$Y$ los hermanos dijeron:

- ¿Ve? Bien seco qui amaneció. ¡Cómo se malogró aquel! ¿Qué desgracia le ocurriría?

A poco tiempo Casico arregló viaje callaíto la boca, y cuando ya salía, se despidió de sus padres y de su hermano y dijo que se iba a buscar fortuna. El otro si había ido a casase con bonitya y éste se iba a conseguir plata.

La madre se quedó llorando.
Monte aentro, monte aentro, Casico se fue encontrando muchos ostáculos, pero al fin los venció todos. Pero sin topar qué comer ni aonde dormir, se sintió desfallecer. Hasta que, de golpe, dio con la cruz que había clavao Casicón.

- ¿Ve? Por aquí pasó aquel... -pensó. Hizo otra cruz igual, la clavó al lao y ai mismo se acostó a dormir.

Durmió bien. A la mañanita volvió a coger la trocha.

Llegóa la ciudá, pero un encontró un trabajo halagador y determinó seguir andando. Hasta que llegó al caserío. Golpió la puerta de la vieja que comía gente:

A ver, mi señora, si me da posaíta...

Cómo no, joven. Dentre, dentre con toda confianza. Aquí yo le arreglo su buena comida y su buena dormida.

Dios le pague, señora.

Así que la vieja vio el perro, dice:

Eso sí: el perrito ese me lo amarra ajuera. Tome, con esto. - Y le dio los tres pelos. La vieja se metió en la cocina a funcionar muy atareada, y al momento volvió con su buen plato de frisoles con garra, con yuquita, chicharrones y demás. $Y$ este hombre va y se pone a jartar sin pensión de ninguna laya y mordisco de arepa y cucharada de frisoles y revuélvale yuquita y vaya arrempujando con traguitos de leche recién ordeñada en tutuma...

¡Cuando, mijo! ¡La vieja con ese istrumento di hacha, voliándola que ni un arriador!

Casico aimismo l'echó mano a su peinilla y si agarró con la vieja más de media hora, hasta que de pronto la vieja lo logró y ai lo dejó tendido. Endespués, a escuartizalo y a comer cristiano.

Al otro día maneció seco el naranjito d'él. 
¡Virgen del Carmen, ya van dos! - gritó Casimba.

Casiquito, el menor de los hijòs, se quedó un tiempo ayudándoles a los viejos y bregando por consolalos. Ese sí qu'era buen hijo. Pero al cabo di un tiempo..., “ $\mathrm{i} \mathrm{E}$ ! Yo teo qui averiguar qué fue lo que les pasó a mis hermanos. Esta no es conmigo" -se dijo. Arregló, pues, el morralito, l'echó mano a la peinilla, silbó al perro, y salió. A los papes les dijo:

- Me voy a hacer plata, peru harta, y a casame con la más linda.

- ¡Ay, m'hijo, no te vas! - lloraba la madre-. Mirá que ya perdí dos hijos y si te llega a pasar algo a vos, yo no puedo con la pena. No te vas...

Casiquito siempre se fue, secándose aquí así un par de lágrimas. $Y$ pegó monte aentro. Dele pata y dele pata. Cuando ya'staba muy cansao un encontró aonde posar. Andaba y andaba y ya creía qu'estaba perdido, dando vueltas como los que se pierden en el monte, y hasta con miedito de encontrase por ai con la Patasola o algo por el estilo. Ya, muy cansao, encontró las cruces qui habían clavao los hermanos y así supo que habían pasao por ai. Clavó otra cruz y se dejó caer.

Al día siguiente amaneció como lloviznando. Casiquito se madrugó y dijo a andar; en el morralito llevaba dulc'e libra y unos tabaquitos, de modo que no le faltaran las fuerzas y tenía con qué distraese a ratos. Hasta que llegó a la ciudá. No se demoró nada. Siguió adelante, adelante, hasta que pasó por la casa de la vieja que comía gente.

Voy a seguir otro ratico a ver si me rinde la jornada.

¡Cuando en esas se larga qué aguacero! Entonces llegó a la puerta de la vieja, pa guarecese.

Quédese - le dijo ella -. Dentre, que ya está muy tarde. Aquí tiene usté la comida libre y la dormida ...
Él no pensaba quedase, cuando, de pronto, devisó allá las peinillas de los dos hermanos, colgadas en una percha. Miró pa entro y vio los perros amarrados con tres cadenas cada uno.

¡Upalle! Esto está grave - pensó -, pero no le dijo palabra a la vieja. No se la dejó conocer. Apenas entró a la casa, ojo pa lao y lao, le dice la vieja:

Perdone joven, pero deje el perrito amarrao allá ajuera. Tome estos tres pelos para que lo amarre bien.

Casiquito hizo como que lu amarraba, pero con la barbera picó los tres pelos y los botó. Se agachó onde el perro y le dijo pasitico en l'oreja:

[...] Tate quieto ai, carranchoso; pero cuando yo grite: "Mi Dios y mi perro, favoreceme", brincás.

Apenas Casiquito volvió a entrar, corrió la vieja a arreglale la comida y le sacó pero qué sancochu'e gallina con su buena arep'e chócolo calientita y con medio aguacate,

El muchacho comía, sí; pero como era avispao y ya'staba orejón con lo que había visto, no se sentó onde la vieja le dijo, sinó que se sentó en un tronco qu'estaba tirao en medio patio.

Cuando... a nada, sintió que la vieja venía detrás con mañita. Y ai mismo saltó:

¡Qué cuentu'e comida ni nada! Rumbó todo a los infiernos y si armó de su peinillita.

¡Taque, taque, chipulún! Golpe va y golpe viene; la peinillita y el hacha sacaban un chispero que se podía prender candela. Casiquito peliaba muy bien y sabía muchas paradas, pero, como l'hacha era más larga,, la vieja se le'staba viniendo encima. Cuando ya se vio perdido, gritó: “iiMi Dios y mi perro, favoreceme!!".

$Y$ brinca ai mismo ese perro ¿oiga? $Y$ me paña la viej'e los gañotes y al suelo con ella. Y toda- 
vía en el suelo la vieja voliaba l'hacha, pero lo que fue peinilla le sobró para dar y convidar.

Casiquito le hizo su buen entierro, eso sí...

Después dentró a la casa y se puso a reblujar, a ver qué topaba por ai. $Y$ s'encontró en el bondo de un baúl una toallita misteriosa que decía uno: "Mi Dios y caigan manjares y vino del cielo..." y todo caía. Un era sino tener prevención, porque si un plato había, un plato se llenaba; y si diez eran, todos diez se taquiaban de cosas a cuál más deliciosa.

Casiquito se guardó bien guardada la toallita y siguió buscando, a ver....

También dio con una pieza llena di oro y con otra llena de plata y de tesoros muy lindos. (Jaramillo Londoño, 1958:32)

Casiquito sigue recorriendo el mundo y encuentra un hombre que tenía una lira que resucitaba muertos, se la cambia por la toallita de los manjares, retorna y resucita a sus hermanos y logran cumplir sus deseos.

Para cerrar este capítulo, me gustaría mencionar una síntesis de "El Conejo, el sapo y el tigre", un cuento tradicional en lengua palenquera, con el sello de los personajes de la cultura negra, entre los cuales se destaca el pícaro conejo. Se trata de una trascripción y traducción hecha por Carlos Patiño Roselli (Niño, 1978: 387) y recopilada en San Basilio de Palenque:

El original sonaría así:

Tigre ase un losa. Entonse conejo ase uto losita. Entonse losita conejo era un losita chikitiko ke akansaba ni pa kumé un día nu; y losa tigre era ngandísimu. Entonse tigre á teneba de to: á teneba yuca, patiya, maí; de to á teneba tigre aí. Entonse, kuando tigre dekuidaba, conejo aseba yegá ku zorra a robá maí aí, patiya, meló, de to".

El tigre hizo una roza. Entonces el conejo hizo otra rocita, chiquitica, que no alcanzaba para comer un día; y la roza del tigre era grandísima, y tenía de todo: yuca, patilla, maíz.

Cuando el tigre se descuidaba, el conejo iba con la zorra a robar maíz, y el tigre se dio cuenta, $y$ entonces puso una muchacha ahí.

Cuando el conejo volvió, encontró el rancho del tigre bien organizado y dijo: "tío tigre tiene muchacha, tiene cerveza, tiene ron, tiene de todo aquí; hoy sí mi borrachera será grande". Entonces el conejo sacó una baraja y le dijo a la muchacha que echaran una jugada, pero la muchacha no le contestó.

El conejo tiró dos cartas, y cuando la muchacha no tomó la carta el conejo dijo "niña, yo gạné, yo gané niña, si tú no me pagas, yo mismo me pago", y agarró la plata y se la echó en su bolsa.

Luego pidió cerveza, pero la muchacha no le contestó y él mismo se sirvió.

Luego se quedó mirando a la joven y dijo "Tío tigre tiene esa muchacha bonita aquí en el rancho; carajo, la voy a besar".

Cuando el conejo besó a la muchacha ¡Tran! Se quedó pegado. Entonces le dijo que si no lo soltaba, le daba un puño, se lo dio y le quedó la mano pegada, y luego la otra, y la barriga, $y$ las paticas.

Cuando llegó el tigre y encontró el conejo pegado, dijo que iba a hacer un sancocho con él, y llamó al sapo para que lo cuidara mientras buscaba leña para encender el fogón.

El conejo convenció al sapo de que lo dejara ir, y el sapo le dijo al tigre que lo tirara a la laguna.

Desde entonces, ni conejo ni sapo se dejan coger del tigre.

2 En Literatura de Colombia aborigen, obra a cargo de Hugo Niño (1978), varios relatores del Palenque de San Basilio, Bolívar. Transcriptor y traductor Carlos Patiño Roselli. 


\section{Conclusión}

En alguna oportunidad conversaba con Jairo Aníbal Niño (entre cuyas obras se destacan Zoro, ganadora del Premio Enka de Literatura Infantil en 1977; De las alas caracoli; Dalia y Zazir; $R a-$ zzgo, Indo y Zaz, entre otras; y los libros de poemas La alegría de querer y Preguntario), acerca del permanente debate que suscita la pregunta chay literatura infantil? La respuesta de mi compadre fue sencilla: "no existen sino dos categorías para la literatura: la buena y la mala".

Para la investigadora Lucía Borrero (2001):

[...] a finales de 1970 comienza el controvertido boom de la literatura infantil y juvenil en Colombia [...] y se pueden señalar tres códigos al centro de nuestra narrativa contemporánea: 1) La vasta tradición oral representada en expresiones de nuestro folclor -cantos, adivinanzas, retahílas; trabalenguas, juegos de palabras- y en recopilaciones de leyendas que revelan la visión del mundo de los pueblos indígenas. 2) Las obras de corte realista social, legado de los autores costumbristas del siglo pasado. 3) Las narraciones originales de corte fantástico que surgen a finales de 1970 y que retoman elementos del primer código, en torno a los cuales se anticipa ya un interesante punto de bifurcación.

El afán de crear categorías y establecer clasificaciones, como lo mencionaba al principio de este texto, se ha querido encasillar ciertos autores y textos, y así se han considerado que Rafael Pombo con sus Cuentos Pintados (Orjuela, 1975), José Manuel Marroquín (Casas, 1927), Eduardo Caballero Calderón con su Historia en cuentos (1972), Hugo Niño, Leopoldo Berdella de la Espriella (Koku-yó, mensajero del sol, 1988), Pilar Lozano (Colombia, mi abuelo y yo, 1998), Yolanda Reyes con su célebre Terror de Sexto B, Triunfo Arciniegas, autor de Las batallas de Rosalino (1998), Evelio José Rosero (El aprendiz de mago, 1992), Jairo Aníbal y yo con Los amigos del hombre (1979), entre muchos nombres, seamos "escritores y escritoras para niños", por ser, en cierto sentido, resultado del auge de esta forma de ex- presión mencionado por Lucía Borrero, a partir del Premio Enka, y posteriormente el Premio Norma Fundalectura.

Yo creo que somos escritores a secas, y seguiremos siéndolo en la medida en que comprometamos nuestra vida con nuestro trabajo, y que no nos olvidemos que la fantasía y la magia de la cotidianidad siempre están al alcance de la mano.

\section{Bibliografía}

Andersen, Hans Christian. (1992). Cuentos. México: Editorial Porrúa.

Anónimo. (1998). Las mil y una noches. Barcelona: Círculo de Lectores.

Anónimo. (2000). Popol-Vuh. Las antiguas historias del quiché. Versión, introducción y notas de Adrián Recinos. Guatemala.

Arciniegas, Triunfo. (1988). Las batallas de Rosalino. Bogotá: Carlos Valencia Editores.

Barthes, Roland. (1992). Lo obvio y lo obtuso, imágenes, gestos, voces. Bacelona: Editorial Paidós.

Berdella de la Espriella, Leopoldo. (1988). Kokuyó, mensajero del sol. Bogotá: Carlos Valencia Editores.

Bettelheim, Bruno. (1981). Psicoanálisis de los cuentos de hadas. La extraordinaria importancia de los cuentos de badas para la formación moral e intelectual de los niños. Barcelona: Editorial Crítica.

Borrero, Lucía. (2001). Puntos de bifurcación en la narrativa infantil y juvenil reciente en Colombia, tendencias en su evolución y perspectivas de desarrollo futuro. Bogotá: fotocopia cedida por la autora.

Caballero Calderón, Eduardo. (1972). El almirante niño y otros cuentos. Bogotá: Instituto Colombiano de Cultura.

Carrasquilla, Tomás. (1952). Obras completas. Madrid: Editorial Epesa.

Casas, José Joaquín. (1927). Semblanza de don José Manuel Marroquín. Bogotá: Editorial Minerva.

Curtin, Jeremiah. (1995). Creation Myths of America. London: Bracken Books. 
Esopo. (1995). Fábulas. Barcelona: Editorial Planeta.

Grimm, Jacobo y Wilhelm. (1999). Cuentos de los bermanos Grimm. México: Editorial Porrúa.

Jaramillo, Euclides. (1950). Las aventuras del picaro tio conejo. Bogotá: Editorial Iqueima.

Jaramillo Londoño, Agustín. (1958). Cosecha de cuentos: Del folklore de Antioquia). Medellín: Editorial Bedout.

Jorgenson, T. (1933). History of Norwegian Literature. New York: Penguin Books.

Knappert, Jan y Pelizzoli, Francesca. (1988). Dioses y espiritus de la mitologia africana. Madrid: Editorial Anaya.

León Rey, José Antonio. (1980). El pueblo relata. Bogotá: Ediciones del Instituto Caro y Cuervo.

Lozano, Pilar. (1988). Colombia, mi abuelo y yo. Bogotá: Editorial Panamericana.

Menéndez Pidal, Ramón. (1924). Poesía juglaresca y juglares. Aspectos de la bistoria literaria y cultural de España, hp. de la Rey, de Archivos, Olózaga, 1, Madrid.

Mujica, Elisa. (1984). Raices del cuento popular en Colombia. Boletín de la Academia Colombiana. Tomo XXXIV. No. 146. Bogotá.

Niño, Hugo (comp.). (1978). Literatura de Colombia aborigen, en pos de la palabra. Bogotá: Instituto Colombiano de Cultura.

----. (1996). "Otra vez: la doble historia de las epopeyas míticas amazónicas", en Revista Casa de las Américas, No 204.

Niño, Jairo Aníbal. (1986). Dalia y Zazir. Bogotá: Carlos Valencia Editores.

----. (1994). Preguntario. Bogotá: Panamericana Editorial.

----. (2004). Zoro. Bogotá: Panamericana Editorial.

Orjuela, Héctor. (1975). La obra poética de Rafael Pombo. Bogotá: Ediciones del Instituto Caro y Cuervo.

Oviedo, José Miguel. (1997). Historia de la literatura hispanoamericana, tomo 1. Madrid: Alianza Universidad.
Palma, Milagros. (1993). La mujer es puro cuento, feminidad aborigen y mestiza. Bogotá: Tercer Mundo Editores.

Peláez, Jesús (ed.). (1988). Los judíos y Lucena, bistoria, pensamiento y poesia. Córdoba: Ediciones El Almendro y el Excmo. Ayuntamiento de Lucena.

Perrault, Charles. (1997). Cuentos de Perrault. México: Editorial Porrúa.

Propp, Vladimir. (1984). Las raíces históricas del cuento. Madrid: Editorial Fundamentos.

----. (1985). Morfología del cuento. Madrid: Ediciones Akal.

Reyes, Yolanda. (1995). El terror de sexto B. Bogotá: Editorial Alfaguara.

Román, Celso. (1979). Los amigos del hombre. Medellín: Editorial Colina.

----. (2006). Los animales domésticos y electrodomésticos. Bogotá: Panamericana Editorial.

-----. (2007). Las cosas de la casa. Bogotá: Panamericana Editorial.

Rosero, Evelio José. (1992). El aprendiz de mago. Bogotá: Ediciones del Instituto Colombiano de Cultura.

Santa Biblia, Antiguo y Nuevo Testamento. Sociedades Bíblicas en América Latina: 1960.

Uricoechea, Ezequiel. (1984). "Memoria sobre las antigüedades neogranadinas". Biblioteca Banco Popular Volumen 24.

Vélez de Piedrahita, Rocío. (1986). Guia de literatura infantil. Medellín: Ediciones Secretaría de Educación y Cultura.

Word, Marion y Sibbick, John. (1987). Espiritus, héroes y cazadores de la mitologia de los indios norteamericanos. Madrid: Editorial Anaya.

Yolen, Jane. (1986). Favorite Folk Tales from around the World. New York: Pantheon Books.

Zimmer, Heinrich. (1977). El rey y el cadáver; cuentos psicológicos sobre la conquista del mal. Compilados por Joseph Campbell. Traducción, Ramón Alcalde. Buenos Aires: Editorial Marymar. 